\title{
Human Papillomavirus 16/18 Infections in Lung Cancer Patients in Mexico
}

\author{
Isaías Badillo-Almaraz ${ }^{\mathrm{a}, \mathrm{c}}$ Pablo Zapata-Benavides ${ }^{\mathrm{a}}$ Santiago Saavedra-Alonso ${ }^{\mathrm{a}}$ \\ Diana Zamora-Avila ${ }^{b}$ Diana Reséndez-Pérez ${ }^{a}$ Reyes Tamez-Guerra ${ }^{a}$ \\ Rafael Herrera-Esparzac Cristina Rodríguez-Padilla ${ }^{a}$
}

\begin{abstract}
a Universidad Autónoma de Nuevo León (UANL), Facultad de Ciencias Biológicas, Departamento de Microbiología e Inmunología, Ciudad Universitaria, San Nicolás de los Garza, bUANL, Facultad de Medicina Veterinaria y Zootecnia, Departamento de Genética, Campus de Ciencias Agropecuarias, Escobedo, and 'Universidad Autónoma de Zacatecas (UAZ), Facultad de Medicina Humana, Ciudad Universitaria, Hospital General 'Luz González Cosío', and Centro de Biología Experimental, UAZ, Guadalupe, Mexico
\end{abstract}

\section{Key Words}

Human papillomavirus · Lung cancer $\cdot$ Mexico

\begin{abstract}
Background/Aims: Human papillomavirus (HPV) is an epitheliotropic, double-stranded DNA virus, and its high-risk genotypes are associated with human cancer. HPV genome has been detected in lung carcinomas in certain places around the world, including Mexico; however, the prevalence of this is unclear. In this study, we examine the frequency of highrisk HPV 16/18 in lung cancer tissues from a Mexican population. Methods: 39 lung cancer specimens were analyzed by polymerase chain reaction (PCR) using HPV GP5+/GP6+ primers and then were genotyped using specific primers to HPV 16/18. Additionally, in situ hybridization (ISH) was performed using BIO-labeled oligonucleotide probes. Results: Our results identified 15 positive cases (38.46\%) for HPV 16 and 1 positive case $(2.56 \%)$ for HPV 18 by PCR. ISH showed the presence of HPV DNA in 13 of 16 (81\%) samples, in agreement with the PCR results. Conclusions: In this study, we detected HPV 16/18 gene sequences in lung cancer samples obtained from Mexican patients by PCR and ISH. We found the highest prevalence of HPV 16 infection in lung adenocar-
\end{abstract}

cinomas, suggesting that HPV infection may be associated with lung cancer. However, further studies are needed to elucidate the role of HPV in lung carcinogenesis.

Copyright $\odot 2013$ S. Karger AG, Basel

\section{Introduction}

Lung cancer is the second most prevalent malignant tumor among both men and women and is the leading cause of cancer deaths in Mexico. In addition, the death rate due to lung cancer is increasing $[1,2]$. Cigarette smoking is considered to be the most important risk factor. However, it is conceivable that environmental factors are associated with lung carcinogenesis, such as diesel fumes, wood smoke, silica, asbestos, arsenic, and residential radon exposure $[3,4]$. Recently, a viral etiology of lung cancer has been proposed [5]. Several viral nucleic acid sequences have been detected in lung pathologies, including those of the Epstein-Barr virus in squamous cell carcinoma (SQC) and adenocarcinoma of the lung $[6,7]$, those of zoonotic viruses such as Jaagsiekte sheep retrovirus in sheep breeders who develop lung cancer [8], and recently those of human papillomavirus (HPV) in lung cancer [9-15].

\section{KARGER}

(C) 2013 S. Karger AG, Basel

0300-5526/13/0565-0310\$38.00/0

E-Mail karger@karger.com

www.karger.com/int
Isaías Badillo-Almaraz

Unidad Académica Medicina Humana y Centro de Biología Experimental

Universidad Autónoma de Zacatecas (UAZ)

Zacatecas 98000 (Mexico)

E-Mail jibadial@yahoo.com.mx 
HPV infection may be related to pulmonary tumorigenesis; etiological involvement of high-risk HPV in the development of lung cancer was originally postulated by Syrjänen [9] and confirmed in other studies that most frequently detected the HPV 16/18 genotypes. HPV infection is more frequently associated with non-smoking lung cancer patients $[12,13]$.

In a recent meta-analysis, 100 studies of the literature reporting HPV detection in lung cancer were evaluated, covering 7,381 lung cancer cases analyzed for HPV from different geographical regions. Altogether, 1,653 (22.4\%) samples tested HPV-positive [16].

HPV is an epitheliotropic virus, and it is possible that high-risk types (HPV 16 and 18) contribute to lung cancer as co-carcinogens. Several studies implicating HPV in bronchial carcinogenesis have found an identical pattern to that observed in squamous cell tumors currently classified as emerging HPV lesions, for example those of the oral cavity, esophagus, larynx, and conjunctiva [10].

Studies of the prevalence of HPV infection in lung cancer have reported incidences of $69 \%$ in Finland, 78\% in Norway, $55 \%$ in Taiwan, $22 \%$ in Italy, and $5 \%$ in India $5 \%$. However, a study performed in Greece did not support a role of HPV in lung carcinogenesis [9, 11-14]. In Latin America, the presence of the HPV genome in lung cancer tissues has been reported at $29 \%$ in Chile, $8 \%$ in Peru, and 33\% in Mexico [15]. This work strengthens the few studies conducted in Latin America.

Here, we search for high-risk HPV 16/18 gene sequences in lung cancer tissues from a Mexican population.

\section{Material and Methods}

\section{Sample Collection}

A total of 39 non-small cell lung cancer specimens were examined, 14 from female patients and 25 from male patients. The average age of these patients was 55 years. 20 samples were collected of several lung pathologies, such as samples of thoracic surgery, bronchoscopic biopsy, and bronchoalveolar lavage and pleural biopsy. All samples were obtained from the Hospital Regional de Zacatecas in Mexico City during the period from 2006 to 2009. Requests of the resected tissue specimens were under consent by patients, approved by the internal ethics committee, and carried out in accordance with the Helsinki Declaration. SiHa and HeLa cell lines were obtained from the American Type Culture Collection (Manassas, Va., USA) and cultured and maintained in Dulbecco's modified Eagle's medium (DMEMF-12; Life Technologies, Carlsbad, Calif., USA) supplemented with $10 \%$ fetal bovine serum, $100 \mathrm{U} / \mathrm{ml}$ penicillin, and $100 \mathrm{~g} / \mathrm{ml}$ streptomycin (Gibco, Grand Island, NY, USA). Cell lines were incubated in a humidified chamber at $37^{\circ}$ in a $95 \% \mathrm{O}_{2}$ and $5 \% \mathrm{CO}_{2}$ atmosphere and were used as positive controls.

HPV 16/18 in Mexican Lung Cancer Patients
Detection of HPV Sequences by Polymerase Chain Reaction

(PCR)

DNA was extracted from tissue samples and cell lines using DNAzol genomic DNA isolation reagent (Molecular Research Center, Inc., Cincinnati, Ohio, USA) following the manufacturer's instructions. The DNA concentration was determined by measuring the 260/280 $\mathrm{nm}$ absorbance of each sample with a Pharmacia Biotech Ultrospec 3000 (Milton Keynes, UK).

DNA quality was assessed by amplifying a 192-bp fragment of the $\beta$-globin gene using a set of $\mathrm{PCO} 3 / \mathrm{PCO} 4$ primers: $5^{\prime}$-ACACAACTGTGTTCACTAGC- $3^{\prime}$ and $5^{\prime}$-CAACTTCATCCACGTT CACC-3', respectively [14].

HPV DNA was detected using GP5+/GP6+ primers (forward primer $5^{\prime}$-TTTGTTACTGTGGTAGATACTAC- $3^{\prime}$ and reverse primer $5^{\prime}$-GAAAAATAAACTGTAAATCATATTC- $3^{\prime}$ ) to amplify a 150-bp fragment of L1 gene using the following specifications: $94^{\circ}$ for $2 \mathrm{~min}, 40$ cycles of $94^{\circ}$ for $45 \mathrm{~s}, 66^{\circ}$ for $5 \mathrm{~s}, 71^{\circ}$ for $1.5 \mathrm{~min}$, and a final extension of $10 \mathrm{~min}$ at $72^{\circ}$ [17].

To confirm the detection of HPV types 16 and 18, a PCR amplification was performed using primers specific to either HPV 16 or HPV 18 to amplify 227- and 194-bp products, respectively (16 VPH up 5'-TACTAACTTTAAGGAGTACC-3' $16 \mathrm{VPH} \mathrm{dn}$ $5^{\prime}$-GTGTATGTTTTTGACAAGCAATT- $3^{\prime}$ and VPH 18 up $5^{\prime}$-CC AAATTTAAGCAGTATAGC-3' VPH 18 dn $5^{\prime}$-TTGTACAAAA CGATATGTATCCA- $\left.3^{\prime}\right)$. The amplification was performed using the following specifications: $94^{\circ}$ for $4 \mathrm{~min}, 35$ cycles of $94^{\circ}$ for $30 \mathrm{~s}$, $50^{\circ}$ for $50 \mathrm{~s}, 72^{\circ}$ for $40 \mathrm{~s}$, and $72^{\circ}$ for $5 \mathrm{~min}$ [13].

PCR products were separated by electrophoresis on $1.2 \%$ agarose gels, and the products were visualized with ethidium bromide and photographed under ultraviolet light.

The purified PCR products were submitted for automated DNA sequencing and analyzed with an ABI PRISM 310 Genetic Analyzer. The sequences were compared with HPV genomes submitted to the National Center for Biotechnology Information (NCBI)-GenBank using the BLAST program (NCBI) [18].

\section{In situ Hybridization (ISH)}

ISH to detect HPV types 16 and 18 DNA was performed using BIO-labeled oligonucleotide probes (Pan Path, Amsterdam, the Netherlands) following the manufacturer's instructions. Briefly, deparaffinized and rehydrated $4-\mu \mathrm{m}$ sections were subjected to digestion with pepsin, rinsed with phosphate-buffered saline, and dehydrated. Denaturation and hybridization procedures were performed by applying 1 drop of probe solution to each specimen, incubating slides in a humidified chamber at $95^{\circ}$ for $5 \mathrm{~min}$ and in a moist environment for $16 \mathrm{~h}$ at $37^{\circ}$, and washing with Tris-buffered saline buffer. Detection was performed by applying a horseradish peroxidase-conjugated antidigoxigenin antibody and 2 drops of AEC work solution. The slides were then incubated in the dark to allow the signals to develop. Methyl green was used as a counterstain [19].

\section{Results}

Presence of HPV 16 and 18 Sequences in DNA Isolated from Lung Samples

First, to verify the quality of isolated DNA, PCR was done to amplify the $\beta$-globin gene. All 39 samples 
Fig. 1. PCR amplifications of HPV in lung samples. a PCR for $\beta$-globin gene in lung samples. PCR control to amplify a 192-bp product to analyze DNA integrity. M: 100bp molecular weight marker. Lanes 1-9: lung samples. b PCR amplification of HPV L1 gene sequences in lung samples. Agarose gel electrophoresis of PCR products from the GP5+/GP6+ primer set to amplify a 150bp product. Lane 1: SQC, lanes 2 and 3 are ACs, lane 4: SQC, lane 5: SiHa cell line as positive control, lane 6: negative control, and lane M: 100-bp molecular weight marker. c PCR amplification with HPV 16/18 type-specific primers in lung samples. DNA was re-amplified using the HPV 16/18 typespecific primers. Representative images of lanes positive and negative for (i) HPV 16 (226-bp product) and (ii) HPV 18 (193-bp product). M: 100-bp molecular weight marker. Lanes 1-9: lung samples.

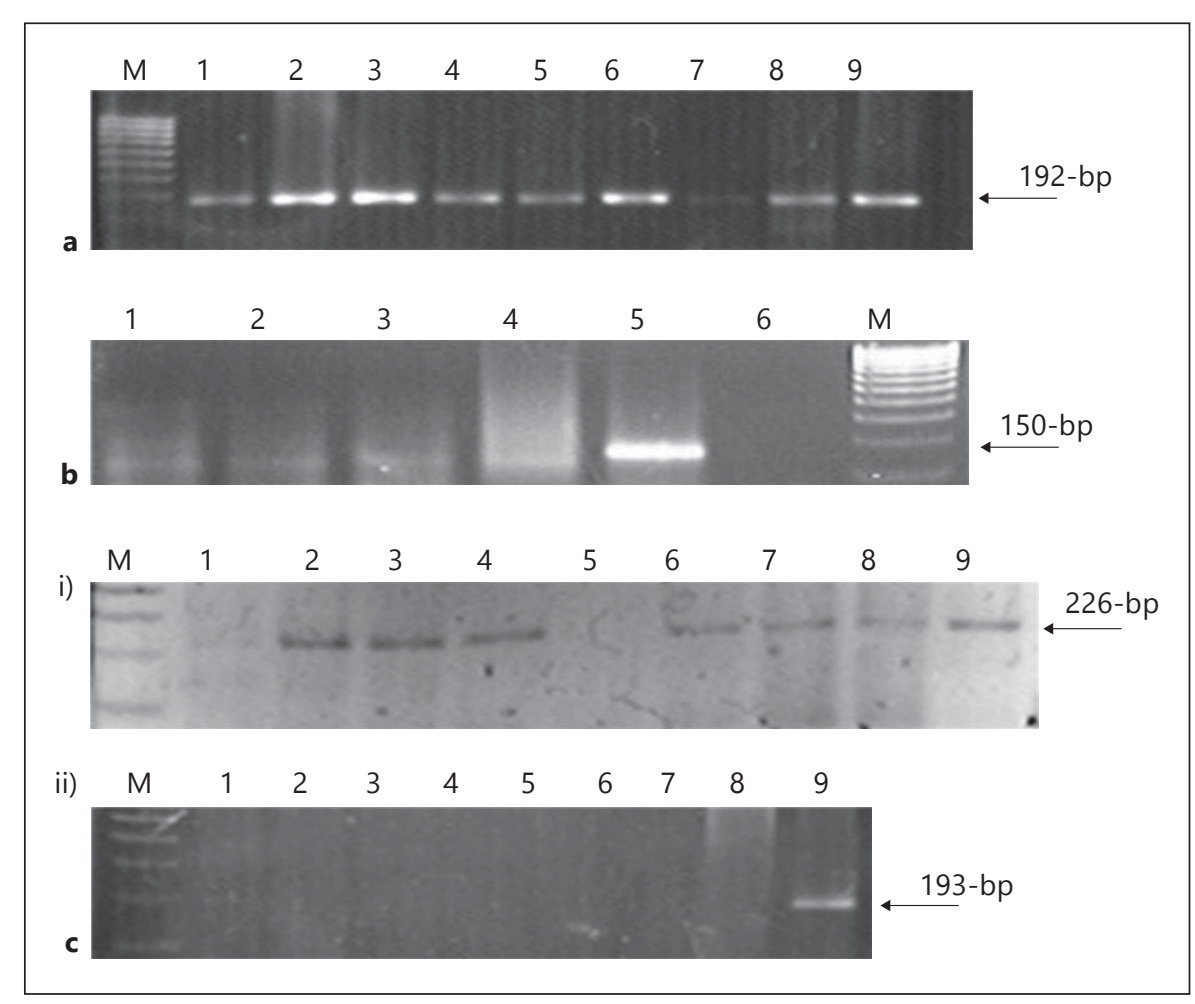

showed the expected amplification of a 192-bp product (fig. 1a).

As a first step in the detection of HPV sequences, PCR screening using the general HPV-specific GP5/ GP6 primers was performed, which led to the detection of the expected 150-bp product in 16 samples (41\%; fig. 1b). Of these HPV-positive cases, 56\% (9 cases) were from male patients and $44 \%$ ( 7 cases) were from female patients.

These 16 positive samples were analyzed in a second round of PCR using primers specific for HPV 16 and HPV 18 to amplify products of 226 and $193 \mathrm{bp}$, respectively (fig. 1c, i and ii). Of the 16 samples, $93.75 \%$ (15 samples) as well as the SiHa cell line positive control were found to be positive for HPV 16 sequences, and 6.25\% (1 sample) as well as the HeLa cell line positive control were found to be positive for HPV 18 sequences.

Two HPV 16 PCR products and one HPV 18 PCR product were sequenced to confirm their identity in the GenBank. The two sequences corresponding to HPV 16 had $100 \%$ homology with the HM596523 sequence, and the only positive HPV 18 sample had 100\% homology with the GQ180792 sequence (fig. 2a, b).

With respect to histopathology, HPV was detected in 10 out of $18(55.5 \%)$ adenocarcinomas (ACs) and 6 out of
21 (28.5\%) SQCs (table 1). HPV 16 was the most frequent HPV type in both ACs and SQCs, and only 1 patient with SQC was positive for HPV 18 (fig. 3a, b).

\section{Presence of HPV DNA in Lung Cancer Samples Confirmed by ISH}

ISH was performed to confirm the presence of HPV sequences in cancer cells and not in normal cells. The results revealed that 13 lung cancer samples were positive for ISH from the 16 samples that were PCR-positive for HPV 16/18 sequences. The distribution of ISH-positive signals revealed that HPV DNA was limited only to the malignant cells and was not observed in adjacent normal cells (fig. 3a, b).

\section{Discussion}

Multiple risk factors have been associated with lung cancer development. Although the main risk factor is smoking, other factors that may influence the development of lung cancer, such as environmental pollution and genetic factors, have been reported [3]. However, not all smokers will develop bronchial cancer in their lifetime, and, in addition, these tumors do occur in patients who have never 


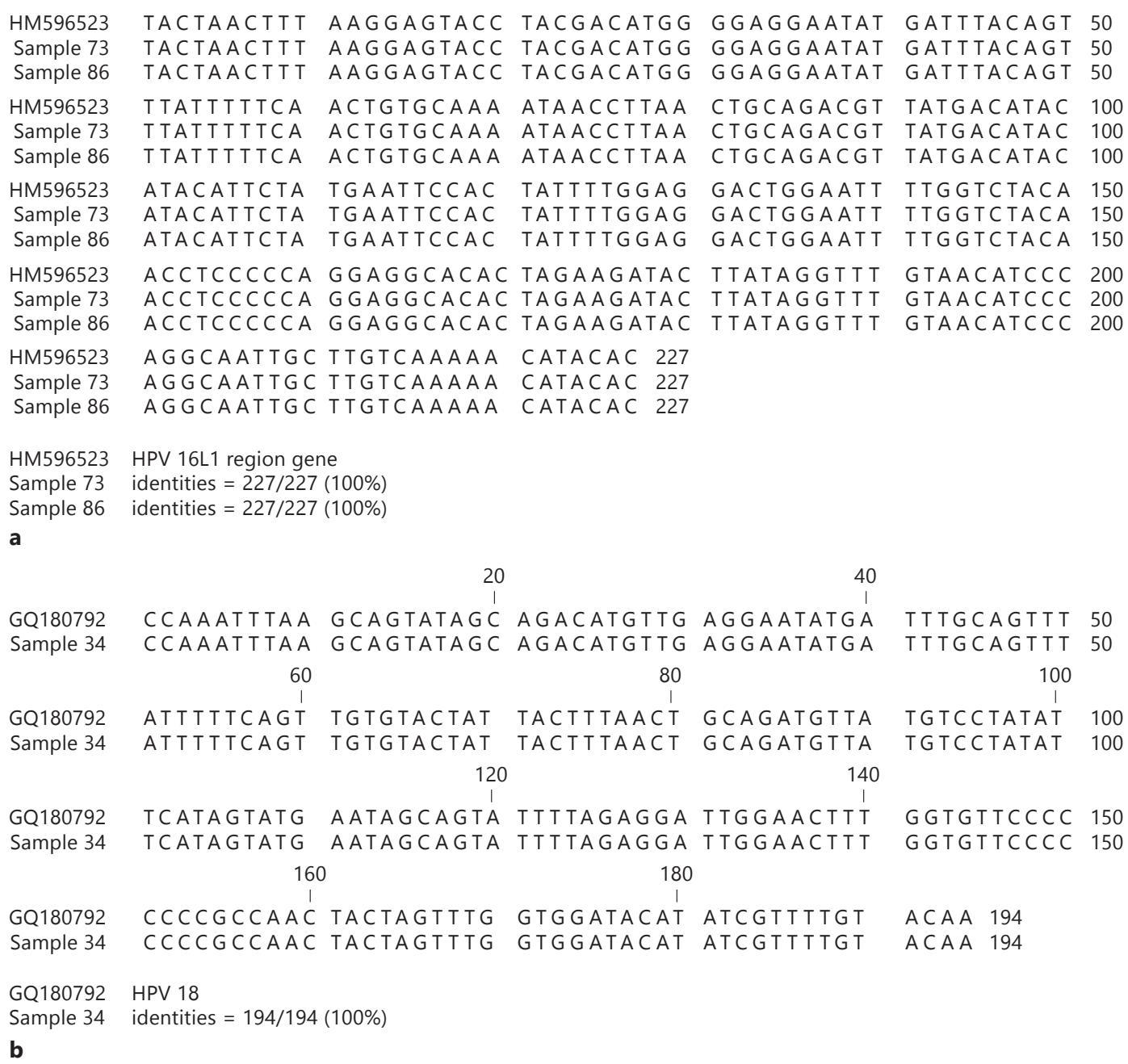

GQ180792 Sample 34 $\begin{array}{ll}20 & 40\end{array}$ CCAAATTTAA GCAGTATAGC AGACATGTTG AGgAATATGA CCAAATTTAA GCAGTATAGC AGACATGTTG AGgAATATGA \begin{tabular}{rrr}
60 & \multicolumn{1}{c}{80} \\
ATTTTTCAGT & & \multicolumn{1}{c}{} \\
TGTTACTAT & TACTTTAACT & GCAGATGTTA
\end{tabular}

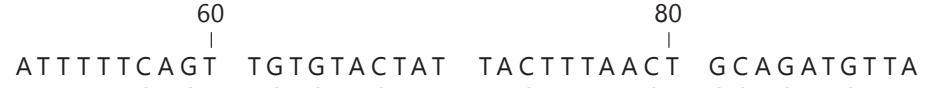

GQ180792 Sample 34 ATTTTTCAGT TGTGTACTAT TACTTTAACT GCAGATGTTA 120 140

GQ180792 Sample 34

TCATAGTATG AATAGCAGTA TTTTAGAgGA TTGGAACTTT TCATAGTATG AATAGCAGTA TTTTAGAGGA TTGGAACTTT 160 180

GQ180792

Sample 34 CCCCGCCAAC TACTAGTTTG GTGGATACAT ATCGTTTTGT CCCCGCCAAC TACTAGTTTG GTGGATACAT ATCGTTTTGT

TTTGCAGTTT 50 TTTGCAGTTT 50 100

TGTCCTATAT 100

TGTCCTATAT 100

GGTGTTCCCC 150 GGTGTTCCCC 150

ACA A 194 ACA A 194

GQ180792 HPV 18

Sample 34 identities $=$ 194/194 $(100 \%)$

b

Fig. 2. HPV 16/18 gene sequencing. Comparison of HPV 16/18 gene sequences amplified from lung samples. HPV 16 sequences were compared with the reported sequence of HM596523, and HPV 18 sequences were compared with GQ180792.

smoked [4]. Interestingly, bronchial carcinomas have also been described in children [10]. The possible involvement of high-risk HPV in bronchial squamous cell lesions was first suggested in 1977 by Syrjänen [9]. Since that time, several studies have confirmed the detection and expression of HPV oncogenes in non-small cell lung cancer [20], although the detection rate in ACs of the lung is much lower [12-15] and many studies failed to demonstrate the presence of HPV DNA [11].

Syrjänen $[16,21,22]$ performed a systematic review and meta-analysis of the literature reporting on HPV detection in lung cancer and reported that the HPV prevalence was $22.4 \%$, which is practically similar as in all other HPV-associated lesions in the respiratory and upper gastrointesti- nal tract. In addition, HPV is an epitheliotropic doublestranded DNA virus, and experimental data accumulated so far suggest that similar mechanisms as those detected in $\mathrm{HPV}$-associated cervical carcinogenesis might also be involved in bronchial carcinogenesis $[9,10,23]$.

Since that time, several studies have confirmed the presence of HPV DNA in lung cancer, although the detection rate in ACs of the lung is much lower [12-15] and many studies failed to demonstrate the presence of HPV DNA [11]. For these reasons, we hypothesize that the involvement of high-risk HPV 16/18 may not be restricted to carcinomas of the uterine cervix but rather may be associated with lung cancer in the Mexican population. The high number of HPV-positive cases in lung 

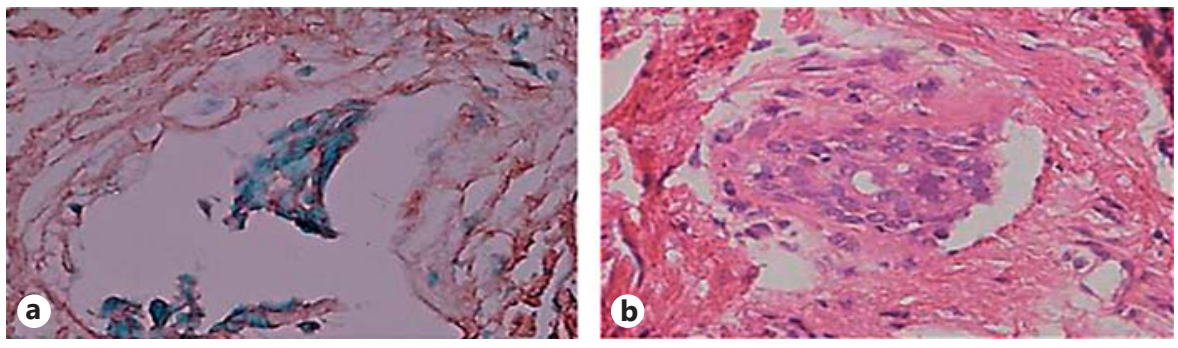

Fig. 3. ISH of HPV 16/18 DNA. a Representative positive signals of HPV 18 DNA by ISH in paraffin sections of SQC. ISH-positive signals in lung tumors are limited to the malignant cells and not observed in adjacent normal cells. Section of squamous cell lung counterstained with methyl green. $\times 200$. b Representative positive signals of HPV 16 DNA by ISH in paraffin sections of AC. Strong HPV 16 DNA signal in a section of lung AC that is not counterstained. $\times 200$.
Table 1. Clinicopathological features of lung SQCs and ACs

\begin{tabular}{lccc}
\hline & SQC, n (\%) & AC, n (\%) & p value $^{1}$ \\
\hline $\begin{array}{l}\text { Total } \\
\text { Gender }\end{array}$ & $21(100)$ & $18(100)$ & \\
$\quad$ Male & $16(76)$ & $9(50)$ & 0.1083 \\
$\quad$ Female & $5(24)$ & $9(50)$ & \\
Smoking & & & \\
$\quad$ Smoker & $15(71)$ & $12(67)$ & 1.0 \\
$\quad$ Non-smoker & $6(29)$ & $6(33)$ & \\
HPV genotype & & & \\
$\quad$ HPV 16 & $5(24)$ & $10(56)$ & 0.375 \\
$\quad$ HPV 18 & $1(5)$ & $0(0)$ & \\
ISH & & & \\
$\quad$ ISH+ & $6(29)$ & $7(39)$ & 0.5196 \\
$\quad$ ISH- & $15(71)$ & $11(61)$ & \\
\end{tabular}

${ }^{1} \mathrm{p}$ values reflecting differences between SQCs and ACs were obtained from Fisher's exact test.

${ }^{2}$ Total number and percent of patients with each histological type.

cancer may reflect the high rate of prevalence of HPV in cervical cancer [24].

HPV may infect both the epithelial respiratory tract and uterine cervix because the preferred sites of entry are the metaplastic squamous cells where HPV interacts with heparin and cell-surface glycosaminoglycans and integrins $[4,5]$ of the squamo-columnar junctions (SCJs) [25]. The presence of SCJs at multiple locations in the respiratory tract is considered to be a prerequisite for the spread of HPV bronchial infections. The most important cause of SCJ formation in the bronchi is cigarette smoking, which frequently triggers the development of squamous metaplasia [9]. Thus, the situation in the bronchi with multiple foci of metaplastic squamous epithelium is reminiscent of that in the transformation zone of the uterine cervix, and these figures are similar to those seen in squamous cell malignances of the airway $[9,23]$.

HPV pathogenesis involves molecular alterations caused by oncoproteins, such as E6 and E7, which facilitate cellular transformation and immortalization. The HPV E6 oncoprotein interacts with the p53 tumor suppressor protein and induces accelerated proteasomal degradation of p53 via a host cell ubiquitin ligase [26]. The E6 oncoprotein also increases cellular telomerase activity, predominantly by inducing transcription of the hTERT gene. The hTERT protein is the catalytic subunit of the telomerase enzyme complex involved in the rate-limiting step and is selectively expressed in a small subset of normal cells (stem cells), tumor tissues, and tumor-derived cell lines [23]. E7 inhibits pRb, which releases E2F and results in the upregulation of INK4A (also known as p16). In addition, E7 seems to stimulate cyclins $\mathrm{A}$ and $\mathrm{E}$ and inactivate the cyclin-dependent kinase inhibitors WAF1 (also known as p21) and KIP1 (also known as p27). In this way, E6 and E7 synergize in cell immortalization and malignant transformation: E6 prevents apoptosis that is induced by high E2F levels and E7 rescues E6 from inhibition by INK4A $[14,15,23,26]$.

The transmission route of HPV detected in lung carcinomas is as yet unclear, although studies on HPV infection and cancers of the oral cavity, esophagus, and lung suggested the possibility of sexual transmission. Recent studies detected identical L1 and E6 HPV 16/18 sequences in lung carcinomas and blood cells. In addition, female cancer patients showed a correlation between HPV 16/18 detection frequencies in lung carcinomas and cervical smears $[14,15]$.

Our results are not in accordance with all previous studies conducted in other countries [5, 12-15]. In Mexico, there has been only one other study reporting the presence of HPV DNA in lung carcinomas, which found 
a frequency of $5 \mathrm{HPV}$-positive samples out of 15 (33\%) [15]. However, the reported variability in HPV detection rates in lung cancer is better explained by geographical study origin and histological types of cancer than by the HPV detection method itself [16].

However, the frequency of HPV-positive samples reported in this study is substantially higher, and HPV sequences were much more frequently found in ACs than in SQCs, similar to findings in northern Europe, Finland, and Norway [27, 28]. In addition, we observed that HPV was slightly more commonly found in the lung samples of males than those of females. These observations suggest the presence of demographic and geographic differences in HPV-related lung carcinogenesis.
In this work, we used the techniques of PCR and ISH. While PCR possessed greater sensitivity, ISH showed that HPV 16/18 DNA sequences were present in malignant cells and not in healthy tissue. It has been suggested that the differences in HPV prevalence reported in lung cancer literature would be explained by the different HPV detection techniques [16]. The HPV-positive cases showed no statistically significant correlation with sex, age, tumor stage (data not shown), or cigarette smoking.

\section{Acknowledgments}

The authors wish to acknowledge the assistance of Dr. Guadalupe Ismael Malagon Santiago for the statistical analysis of data.

\section{References}

1 Franco-Marina F, Villalba-Caloca J: La epidemia de cáncer pulmonar en México. Rev Inst Nal Enf Resp Mex 2001;14:207-214.

2 Medina-Morales F, Salazar-Flores M, GarciaSancho M, Franco-Marina F: Epidemiologia descriptiva del cáncer pulmonar en el Instituto Nacional de Enfermedades Respiratorias. Rev Inst Nal Enf Resp Mex 2002;15:149-152.

-3 Hanahan D, Weinberg RA: The hallmarks of cancer. Cell 2000;100:57-70.

4 Sun S, Schiller JH, Gazdar AF: Lung cancer in never smokers - a different disease. Nature 2007;7:778-790.

5 Brouchet L, Valmary S, Dahan M, Didier A, Galateau-Salle F, Brousset P, Degano B: Detection of oncogenic virus genomes and gene products in lung carcinoma. Br J Cancer 2005; 92:743-746.

6 Kasai K, Sato Y, Kameya T, Inoue H, Yoshimura $\mathrm{H}$, Kon S, Kikuchi K: Incidence of latent infection of Epstein-Barr virus in lung cancers - an analysis of EBER1 expression in lung cancers by in situ hybridization. J Pathol 1994;174:257-265.

7 Chen FF, Yan JJ, Lai WW, Jin YT, Su IJ: Epstein-Barr virus-associated non-small cell lung carcinoma: undifferentiated 'lymphoepithelioma-like' carcinoma as a distinct entity with better prognosis. Cancer 1998;82:2334-2342.

$\checkmark 8$ Rocca S, Sanna MP, Leoni A, Cossu A, Lissia A, Tanda F, Satta MP, Palmieri GP: Presence of jaagsiekte sheep retrovirus in tissue sections from human bronchioloalveolar carcinoma depends on patients' geographical origin. Hum Pathol 2008;39:303-304.

-9 Syrjänen KJ: HPV infections and lung cancer. J Clin Pathol 2002;55:885-891.

10 Zur Hausen H: Papillomaviruses in the causation of human cancers - a brief historical account. Virology 2009;384:260-265.

\section{Gorgoulis VG, Zacharatos P, Kotsinas A, Kyroudi A, Rassidakis AN, Ikonomopoulos JA, Barbatis C, Herrington CS, Kittas C: Hu- man papilloma virus is possibly involved in laryngeal but not in lung carcinogenesis. Hum Pathol 1999;30:274-283.}

$\checkmark 12$ Cheng YW, Chiou HL, Sheu GT, Hsieh LL, Chen JT, Chen CY, Su JM, Lee H: The association of human papillomavirus 16/18 infection with lung cancer among nonsmoking Taiwanese women. Cancer Res 2001;61:2799-2803.

13 Fei Y, Yang J, Hsieh WC, Wu JY, Wu T, Goan YG, Lee H, Cheng YW: Different human papillomavirus 16/18 infection in Chinese nonsmall cell lung cancer patients living in $\mathrm{Wu}$ han China. Jpn J Clin Oncol 2006;36:274-279.

14 Aguayo F, Castillo A, Koriyama C, Higashi M, Itoh T, Capetillo M, Shuyama K, Corvalan A, Eizuru Y, Akiba S: Human papillomavirus 16 is integrated in lung carcinomas: a study in Chile. Br J Cancer 2007;97:85-91.

15 Castillo A, Aguayo F, Koriyama C, Shuyama K, Akiba S, Herrera GR, Carrascal E, Klinge G, Sanchez J, Eizuru Y: Human papillomavirus in lung carcinomas among three Latin American countries. Oncol Rep 2006;15:883-888.

16 Syrjänen K: Detection of human papillomavirus in lung cancer: systematic review and meta-analysis. Anticancer Res 2012;32:32353250.

17 De Roda Husman AM, Walboomers JM, van den Brule AJ, Meijer CJ, Snijders PJ: The use of general primers GP5 and GP6 elongated at their $3^{\prime}$ ends with adjacent highly conserved sequences improves human papillomavirus detection by PCR. J Gen Virol 1995;76:1057-1062.

18 Altschul SF, Madden TL, Schäffer AA, Zhang J, Zhang Z, Miller W, Lipman DJ: 'Gapped BLAST and PSI-BLAST: a new generation of protein database search programs'. Nucleic Acids Res 1997;25:3389-3402.

19 Wilkinson DG: In situ Hybridization: A Practical Approach. Oxford, IRL Press, 1995.
20 Ciotti M, Giuliani L, Ambrogi V, Ronci C, Benedetto A, Mineo TC, Syrjänen K, Favalli $\mathrm{C}$ : Detection and expression of human papillomavirus oncogenes in non-small cell lung cancer. Oncol Rep 2006;16:183-189.

21 Syrjänen K, Syrjänen S: Detection of human papillomavirus in sinonasal carcinoma: systematic review and meta-analysis. Hum Pathol 2012 (E-pub ahead of print).

22 Syrjänen K, Syrjänen S: Detection of human papillomavirus in esophageal papillomas: systematic review and meta-analysis. APMIS 2013;121:363-374.

23 Zur Hausen H: Papillomaviruses and cancer: from basic studies to clinical application. $\mathrm{Na}$ ture 2002;2:342-350.

24 Juárez-Figueroa LA, Wheeler CM, Uribe-Salas FJ, Conde-Glez CJ, Zampilpa-Mejía LG, García-Cisneros S, Hernández-Avila M: Human papillomavirus: a highly prevalent sexually transmitted disease agent among female sex workers from Mexico City. Sex Transm Dis 2001;28:125-130.

25 De la Cruz E, Mohar A, Lizano M: Elementos viricos y celulares que intervienen en el proceso de replicacion del virus del papiloma humano. Rev Oncol 2004;6:263-271.

26 Barbosa MS: The oncogenic role of human papillomavirus proteins. Crit Rev Oncog 1996; 7:1-18.

27 Soini Y, Nuorva K, Kamel D, Pöllänen R, Vähäkangas K, Lehto VP, Pääkkö P: Presence of human papillomavirus DNA and abnormal p53 protein accumulation in lung carcinoma. Thorax 1996;51:887-893.

28 Hennig EM, Suo Z, Karlsen F, Holm R, Thoresen S, Nesland JM: HPV-positive bronchopulmonary carcinomas in women with previous high-grade cervical intraepithelial neoplasia (CIN III). Acta Oncol 1999;38:639-647.
HPV 16/18 in Mexican Lung Cancer Patients
Intervirology 2013;56:310-315 DOI: $10.1159 / 000351075$ 